\title{
A conformational contribution of the luteinizing hormone- receptor ectodomain to receptor activation
}

\author{
Pascal Nurwakagari, Andreas Breit, Claudia Hess, Hagar Salman-Livny', \\ David Ben-Menahem ${ }^{1}$ and Thomas Gudermann \\ Institut für Pharmakologie und Toxikologie, Philipps-Universität Marburg, Karl-von-Frisch-Strasse 1, 35033 Marburg, Germany \\ ${ }^{1}$ Department of Clinical Pharmacology. Faculty of Health Sciences, Ben-Gurion University of the Negev, PO Box 653, Beer Sheba, Israel \\ (Requests for offprints should be addressed to T Gudermann; Email: guderman@staff.uni-marburg.de)
}

\begin{abstract}
Glycoprotein hormone receptors such as the lutropin/chorionic gonadotropin receptor (LHR) are characterized by a large $\mathrm{N}$-terminal ectodomain (ECD), which is responsible for hormone-receptor interactions. For the closely related TSH receptor (TSHR), it has been proposed that the ECD also serves as a tethered inverse agonist. However, the exact role of the LHR-ECD for receptor activation remains elusive. Functional analysis of N-terminally truncated LHR mutants expressed in COS-7 cells revealed that the LHR-ECD does not act as an inverse agonist but facilitates active LHR conformations. This notion is supported by two observations: first, removal of the ECD tended to decrease basal LHR activity and secondly, mutationally induced constitutive receptor activity was diminished for most activating mutations in LHR lacking the ECD. In addition, swapping of the LHR-ECD for the ECD of the closely related TSHR was not sufficient to restore constitutive receptor activity induced by naturally occurring activating heptahelical LHR mutations. Thus, the ECD stabilizes an activation-competent conformation of the heptahelical region. While the full-length LHR fused to the cognate agonist, human chorionic gonadotropin (hCG), showed increased basal activity, fusion proteins between hCG and Nterminally truncated LHR did not yield constitutive receptor activity suggesting an important role of the ECD also for agonist-dependent LHR activity. Our experiments strengthen the concept of a major contribution of the LHR-ECD in the activation mechanism apart from hormone binding and provide evidence for a cooperative model with structural and functional interactions of the ECD and the transmembrane domain.
\end{abstract}

Journal of Molecular Endocrinology (2007) 38, 259-275

\section{Introduction}

The receptors for glycoprotein hormones - luteinizing hormone, human chorionic gonadotropin (hCG), follicle-stimulating hormone (FSH) and thyroid-stimulating hormone (TSH) - belong to the subfamily of leucine-rich repeat (LRR)-containing G proteincoupled receptors (LGR) comprising at least eight structurally related human members (Herpin et al. 2004). A major feature of glycoprotein hormone receptors is the large N-terminal ectodomain (ECD) harboring the structural hallmark of LRR motifs (Fan \& Hendrickson 2005). The crystal structure of human FSH complexed with the N-terminal hormone-binding domain of the human FSH receptor reveals that the LRR domain is composed of ten irregular LRR that all participate in hormone binding (Fan \& Hendrickson 2005). Glycoprotein hormones are heterodimers composed of a common $\alpha$-subunit and a hormone-specific $\beta$-subunit that is responsible for receptor specificity. Yet, both subunits interact with the ECD (Phang et al. 1998, Hong et al. 1999a,b, Fan \& Hendrickson 2005). Although the ECD is responsible for specificity and affinity of ligand-binding (Xie et al. 1990, Braun et al. 1991, Moyle et al. 1994, Bhowmick et al. 1996, Thomas et al. 1996, Phang et al. 1998, Hong et al. 1999a,b, Ascoli et al. 2002, Smits et al. 2003, Vassart et al. 2004, Fan \& Hendrickson 2005), and $G$ protein activation is mediated by the transmembrane domain (TMD; Ascoli et al. 2002, Vassart et al. 2004), the activation mechanism of glycoprotein hormone receptors is still unclear.

Several mechanisms of receptor activation have been proposed. According to one model, the glycoprotein hormone is bound by the ECD, so that distinct portions of the hormone interact with and activate the TMD. This model suggests that once the cognate ligand is bound by the ECD, residues in the hormone, most likely in the common $\alpha$-subunit of the glycoprotein hormones, interact with conserved amino acids present in the serpentine portion of their receptors. As a result, the cAMP signaling cascade common to all glycoprotein hormone receptors is activated. This mechanism is supported by the fact that antibodies against residues of the $\alpha$-subunit of hCG can prevent receptor activation without affecting hormone binding of the lutropin/ chorionic gonadotropin receptor (LHR)-ECD (Couture 
et al. 1996). In agreement with this hypothesis, previous studies have demonstrated that hCG and peptides derived from the hCG $\alpha$-chain can directly activate an LHR variant lacking the ECD (Ji \& Ji 1991, Kundu et al. 1996). In a second model, particularly proposed for the TSH receptor (TSHR), the ECD serves as an inverse agonist stabilizing the transmembrane helices in an inactive conformation. This model implies that hormone binding and activating mutations disengage the inhibitory ECD-TMD interaction (Zhang et al. 1995, 2000, Van Sande et al. 1996, Gruters et al. 1998, Nakabayashi et al. 2000, Nishi et al. 2002, Vlaeminck-Guillem et al. 2002) and is supported by findings that removal of the complete ECD leads to high constitutive receptor activity (Zhang et al. 2000). Consistent with this hypothesis, deletion of portions of the ECD (Zhang et al. 1995) or activating mutations within the ECD (Gruters et al. 1998, Nakabayashi et al. 2000) can result in elevated basal activity. In a third scenario, binding of the hormone to the ECD leads to a conformational change of the receptor so that the ECD is able to act as an endogenous agonist on the TMD. This model is supported by findings that mutations of certain amino acid residues in the C-terminal end of the ECD impair ligand-induced receptor activation without affecting receptor expression or hormone binding (Alvarez et al. 1999). Moreover, deletion of the N-terminal part of the ECD abrogates constitutive receptor activity caused by an activating mutation in the ECD (Sangkuhl et al. 2002). A combination of the second and third model gives rise to an additional mechanism implying that the ECD initially acts as an inverse agonist, but changes its conformation to become an agonist by hormone binding or activating mutations (VlaeminckGuillem et al. 2002).

Here, we examined the role of the ECD for the activation of the LHR. N-terminally modified LHR mutants were generated by site-directed mutagenesis, domain deletion and/or domain swapping. Mutant receptors were functionally analyzed by determining receptor protein expression and insertion into the cell membrane as well as basal and agonist-induced cAMP accumulation. Our results suggest that the LHR-ECD is a major factor for signaling in response to agonist or activating mutations by stabilizing an activation-competent conformation of the heptahelical receptor portion.

\section{Materials and methods}

\section{Materials}

Cell culture media were purchased from PAA Laboratories (Pasching, Austria). Restriction enzymes were obtained from Fermentas GmbH (St Leon-Rot, Germany) and New England Biolabs GmbH (Frankfurt am Main, Germany). QUIKCHANGE site-directed mutagenesis kit and Pfu Turbo DNA polymerase were provided by Stratagene (La Jolla, CA, USA). METAFECTENE transfection reagent was obtained from Biontex (Munich, Germany). Forskolin was provided by Biotrend (Cologne, Germany). Purified hCG was purchased from Calbiochem (Schwalbach, Germany). Horse radish peroxidase (HRP)-labeled and unlabeled rat monoclonal anti-haemagglutinin (HA) antibody (3F10), mouse monoclonal anti-HA antibody (12CA5), FUGENE transfection reagent and COMPLETE MINI protease inhibitor cocktail were obtained from Roche Diagnostics. HRP-conjugated anti-mouse IgG (A-4416), HRP-labeled anti-rabbit antibody (A-6154), fluorescein isothiocyanate-conjugated anti-rat IgG (F-1763), 3-isobutyl-1-methylxanthine and bTSH were obtained from Sigma. Rabbit antiserum against CG $\beta$ of hCG was kindly provided by Irving Boime (Washington University, St Louis, MO, USA). ROTI-BLOCK blocking reagent was obtained from Roth (Karlsruhe, Germany). HYBOND C EXTRA and enhanced chemi luminescence (ECL) detection system were purchased from Amersham Biosciences. DC PROTEIN ASSAY was provided by Bio-Rad Laboratories GmbH. Ten percent phosphate-buffered formalin solution was provided by J T Baker (Deventer, The Netherlands). 1-STEP TURBO TMB-ELISA solution was purchased from Pierce Biotechnology (Rockford, IL, USA).

\section{Construction of mutant LHR}

The cDNA of the hLHR and hTSHR was subcloned into the expression vector pcDps (LHR-pcDps, TSHRpcDps) as described previously (Biebermann et al. 1997, Schulz et al. 1999). In order to permit immunological detection, an HA-tag (YPYDDVPDYA) was inserted into the wild type hTSHR downstream of amino acid 21 and into the wild type hLHR downstream of amino acid 26 by two-step PCR. The cDNA of hV2LHR integrated into the pcDps-vector was kindly provided by Torsten Schöneberg (Sangkuhl et al. 2002; Table 1). Point mutations resulting in naturally occurring activating TMD-mutations (Table 1) were integrated into LHR-pcDps by PCR-based site-directed mutagenesis and a restriction fragment replacement strategy. To generate TSHR-LHR chimeras, an EcoRV site was integrated at nucleotide 1230 of the hTSHR $($ GACATA $\rightarrow$ GATATC) and at nucleotide 1065 of the hLHR (GACATT $\rightarrow$ GATATC) allowing the subcloning of a TSHR-pcDps-fragment encoding for the complete TSHR-ECD into LHR-pcDps by AvrII and EcoRV. To create V2hingeLHR, a PCR fragment encoding for the ECD of the $V_{2} R$ and the amino acid residues 270-357 of the hLHR and ending with an EcoRV site was inserted into V2LHR over the NheI and EcoRV sites. A singlechain hCG variant composed of the $\beta$-subunit genetically fused to the $\alpha$-subunit (CG $\beta \alpha)$ was constructed in 
Table 1 Synopsis of LHR variants used in this study

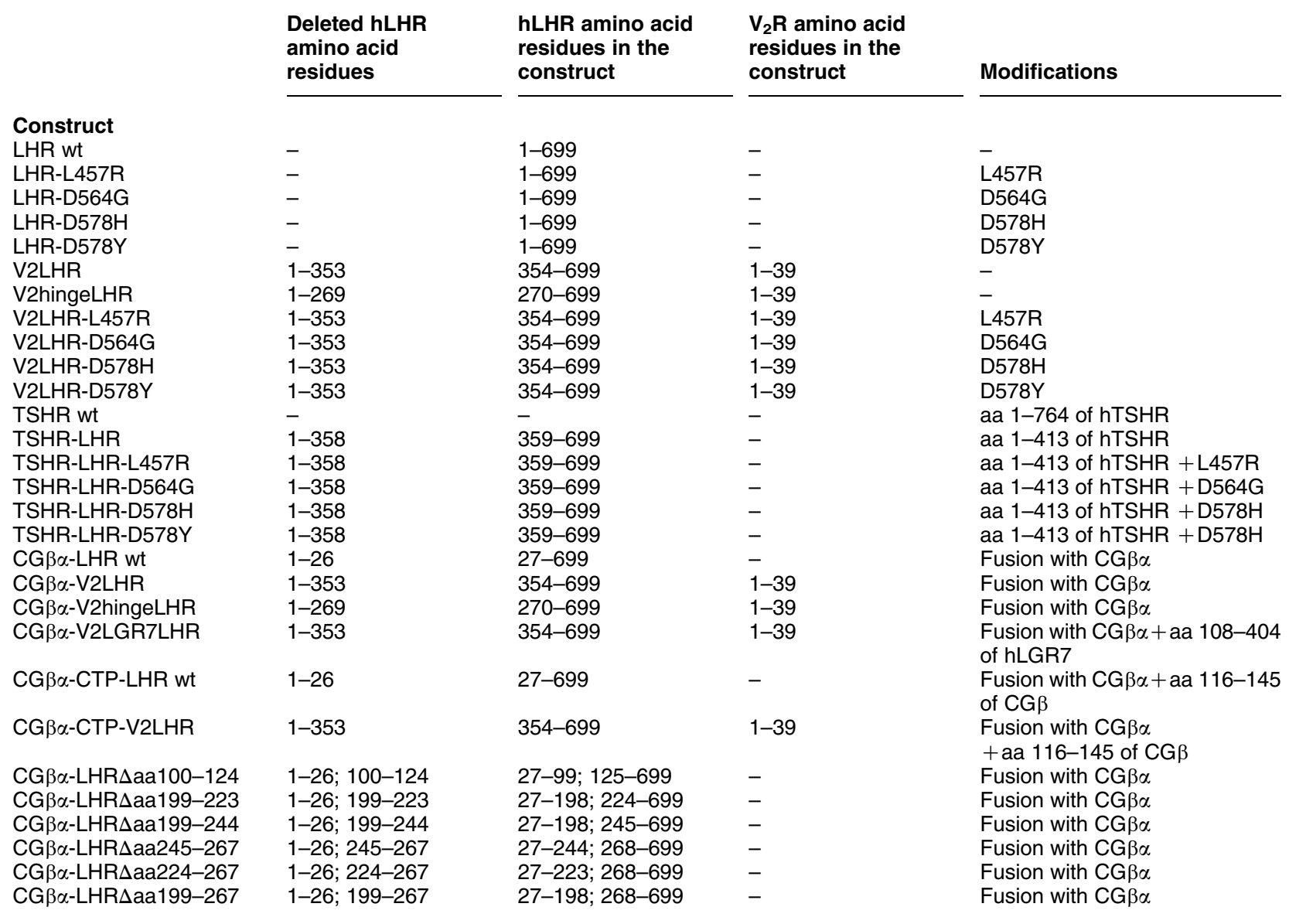

The amino acid residues that were deleted or present in the receptor variants are outlined. The amino acid residue positions refer to the human LHR and to the human $V_{2} R$ (without epitope tags). Single amino acid substitutions and sequences of receptor chimeras are also indicated.

the laboratory of Irving Boime (Sugahara et al. 1995). This single-chain hCG was shown to exhibit similar binding activity as the native heterodimer, but displayed an increased biological activity in vitro and in vivo compared with the native hCG (Sugahara et al. 1995). A PCR fragment encoding for a small non-coding sequence with a BglII site, the single-chain hCG, an HA-tag, and ending with a NheI site in the $\mathrm{V}_{2} \mathrm{R}$ sequence was generated by overlapping PCR and fused to the V2LHR in pcDps over BglII and NheI in order to generate CG $\beta \alpha$-V2LHR. To create a full-length wild type receptor bound to single-chain hCG (CG $\beta \alpha-L H R w t)$, CG $\beta \alpha$-V2LHR-pcDps and LHR-pcDps were digested with BglII and NheI and defined restriction fragments were combined. A flexible linker composed of the C-terminal end of CG $\beta$ (CTP; aa 116-145) was inserted between the single-chain hCG and the HA-tag in CG $\beta \alpha$ CTP-LHR wt and CG $\beta \alpha-$ CTP-V2LHR in two steps: first, an EcoRV restriction site (GATATC) was introduced at the $3^{\prime}$-end of the CG $\alpha$ sequence in CG $\beta \alpha$-LHR wt and
CG $\beta \alpha$-V2LHR by site-directed mutagenesis. In a second step, a PCR-fragment encoding for amino acid (aa) 116 to 145 of CG $\beta$ was subcloned into the EcoRV site of CG $\beta \alpha$-CTP-LHR wt-pcDps and CG $\beta \alpha$-V2LHR-pcDps. In order to design hormone-receptor fusion proteins lacking certain LRR, various portions within the LRR domain were deleted in CG $\beta \alpha$-LHR wt by using the twostep PCR technique. The detailed strategy of construction of each construct is available upon request. The correctness of all constructs was confirmed by dideoxy DNA sequencing.

\section{Cell culture and transient transfections}

COS-7 cells were cultured in Dulbecco's modified Eagle's medium (DMEM) supplemented with $10 \%$ fetal bovine serum, $100 \mathrm{U} / \mathrm{ml}$ penicillin, and $100 \mu \mathrm{g} / \mathrm{ml}$ streptomycin (cell culture medium). Cells were grown at $37^{\circ} \mathrm{C}$ in a humidified $5 \% \mathrm{CO}_{2}$ incubator. Depending on the number of cells seeded, cells were 
transfected with various amounts of DNA using METAFECTENE or FUGENE according to the manufacturer's instructions.

\section{Membrane preparation, SDS-PAGE and western blot analysis}

Sixty hours after transfection, cells from two 10-cm dishes were washed twice in ice-cold PBS and scraped into lysis buffer (25 mM Tris/HCl, pH 7·5, 1 mM EDTA, 1 tablet COMPLETE MINI in $7 \mathrm{ml}$ volume). After $5 \mathrm{~min}$ on ice, cells were homogenized by passing the cell suspension six times through a $0.5 \mathrm{~mm} \times 25 \mathrm{~mm}$ needle attached to a disposable syringe. The lysate was then centrifuged at $600 \mathrm{~g}$ for $10 \mathrm{~min}$ at $4{ }^{\circ} \mathrm{C}$. The supernatant was centrifuged at $100000 \mathrm{~g}$ for $1 \mathrm{~h}$ at $4{ }^{\circ} \mathrm{C}$. The pellet was resuspended in $200 \mu l$ lysis buffer, snap-frozen in liquid $\mathrm{N}_{2}$ and stored at $-80^{\circ} \mathrm{C}$. To prevent glycosylation, after transfection COS-7 cells were incubated with $2 \mu \mathrm{M}$ tunicamycin for $14 \mathrm{~h}$. Protein concentrations of membrane fractions were determined by the DCPROTEIN ASSAY. After addition of $2 \times$ SDS/sample buffer to the probes 75 or $100 \mu \mathrm{g}$ protein were resolved on 7,8 , or $12 \%$ SDS polyacrylamide gels under reducing conditions without boiling. After transfer of proteins to HYBOND CEXTRA membranes, blots were incubated with ROTI-BLOCK blocking reagent at room temperature for $1 \mathrm{~h}$ or overnight at $4^{\circ} \mathrm{C}$. Blots were washed in PBS and then probed with $50 \mathrm{mU} / \mathrm{ml}$ of an HRP-labeled rat monoclonal anti-HA antibody (3F10, Roche Diagnostics) in PBS containing 5\% dry milk at room temperature for $1 \mathrm{~h}$. In contrast, blots of lysates from cells expressing LHR fused to CG $\beta \alpha$ were incubated with a 1:4000 dilution of a rabbit anti-CG $\beta$ antiserum in PBS containing 5\% dry milk and then probed with a dilution of an HRP-labeled goat anti-rabbit IgG (A-6154, Sigma) in PBS containing 5\% dry milk. After washing, signals were visualized by using the ECL detection system.

\section{Cell surface ELISA and immunofluorescence studies}

To evaluate cell surface expression of receptors carrying an HA-tag, we used an indirect cellular ELISA (Schoneberg et al. 1997), further referred to as cell surface ELISA. COS-7 cells were seeded into 24-well plates and transfected with $0 \cdot 6 \mu \mathrm{g}$ DNA and $1 \cdot 8 \mu \mathrm{l}$ METAFECTENE per well. To examine plasma membrane targeting concomitantly with cAMP levels, COS-7 cells were seeded into $10 \mathrm{~cm}$-dishes, transfected with the cDNA of various LHR variants $(2-12 \mu \mathrm{g}$ cDNA per 10-cm dish) using METAFECTENE or FUGENE according to the manufacturer's instructions, and then harvested and seeded into 24-well plates (ELISA) and 12-well plates (cAMP accumulation assay). Forty eight hours after transfection, cells in 24-well plates were fixed with a $10 \%$ formalin solution without disrupting the cell membrane, blocked with DMEM supplemented with $10 \%$ fetal bovine serum, and then incubated with the same medium containing a mouse monoclonal anti-HA antibody (12CA5, Roche Diagnostics). After washing with PBS, cells were incubated with an HRP-conjugated anti-mouse antibody (A-4416, Sigma) in DMEM containing $10 \%$ fetal bovine serum for $1 \mathrm{~h}$. Cells transiently expressing LHR fused to CG $\beta \alpha$ were first incubated with a 1:4000 dilution of a rabbit anti-CG $\beta$ antiserum in DMEM containing 10\% fetal bovine serum and then probed with an HRP-labeled goat anti-rabbit IgG (A-6154, Sigma). After washing, cells were incubated with 1-STEP TURBO TMB-ELISA containing TMB $\left(3,3^{\prime}, 5,5^{\prime}\right.$ tetramethylbenzidine), a substrate for HRP. The enzymatic reaction was stopped by the addition of $1 \mathrm{M} \mathrm{H}_{2} \mathrm{SO}_{4}$, and color development was measured at $450 \mathrm{~nm}$ using an ELISA reader (ELX800G, MWG Biotech). The $A_{450 \mathrm{~nm}}$ readings of untransfected cells were subtracted from $A_{450 \mathrm{~nm}}$ readings of cells expressing HA-tagged receptors.

To examine subcellular distribution of wild type and mutant LHR, immunofluorescence studies were carried out. COS-7 cells were grown on sterilized, $25 \mathrm{~mm}$ glass coverslips in 6-well plates and transfected with $2.5 \mu \mathrm{g}$ DNA and 7.5 $\mu \mathrm{l}$ METAFECTENE per well. At 24 or $48 \mathrm{~h}$ after transfection, cells were fixed with $10 \%$ formalin, probed with $1 \mu \mathrm{g} / \mathrm{ml}$ of a monoclonal rat anti-HA antibody (3F10; Roche Diagnostics), and then incubated with a fluorescein isothiocyanate-labeled anti-rat antibody (F 1763, Sigma). To detect intracellularly retained receptors, cells were preincubated with $0 \cdot 1 \%$ Triton X-100 in PBS for $30 \mathrm{~min}$. Fluorescence microscopy was performed with a confocal laser scanning microscope (LSM 510 META; Zeiss, Jena, Thuringen, Germany).

\section{cAMP accumulation assays}

For cAMP accumulation assays, COS-7 cells were seeded into 12-well plates $\left(0 \cdot 7-1 \times 10^{5}\right.$ COS-7 cells/well) and transfected with $0.5 \mu \mathrm{g}$ DNA and $1.5 \mu \mathrm{l}$ METAFECTENE per well. To examine plasma membrane targeting concomitantly with cAMP levels, COS-7 cells were seeded into $10-\mathrm{cm}$ dishes, transfected with the cDNA of various LHR variants (2-12 $\mu \mathrm{g}$ cDNA per $10-\mathrm{cm}$ dish) using METAFECTENE or FUGENE according to the manufacturer's instructions, and then harvested and seeded into 24-well plates (ELISA) and 12-well plates (cAMP accumulation assay). About 24-48 h after transfection, cells in 12-well plates were prelabeled with $2 \mu \mathrm{Ci} / \mathrm{ml}$ of ${ }^{3} \mathrm{H}$-adenine $(31.7 \mathrm{Ci} / \mathrm{mmol}$, PerkinElmer Life Science, Boston, MA, USA) and incubated overnight. About 18-22 h after labeling, cells were washed once in serum-free DMEM supplemented with $1 \mathrm{mM}$ 3-isobutyl-1-methylxanthine, followed by incubation with the same medium containing $1 \mu \mathrm{M}$ hCG (Calbiochem), $100 \mathrm{mU} / \mathrm{ml} \mathrm{bTSH}$ (Sigma) or $100 \mathrm{mM}$ forskolin (Biotrend) for $1 \mathrm{~h}$ as indicated in the figure 
legends. Thereafter, the medium was discarded and cells were lysed by the addition of $5 \%$ trichloroacetic acid containing $1 \mathrm{mM}$ cAMP and $1 \mathrm{mM}$ ATP. cAMP separation was carried out according to Salomon et al. (1974) and cAMP production as measured by liquid scintillation spectrometry was normalized to basal cAMP accumulation by the wild type LHR. Basal cAMP accumulation of cells expressing V2LHR, V2hingeLHR or the wild type LHR is given as percentage of forskolin $(100 \mu \mathrm{M})$-induced cAMP accumulation determined in cells derived from the same transfection. Basal cAMP accumulation of mock transfected cells was subtracted from the measured cAMP values.

\section{Results}

\section{The ectodomain is required for LHR activation}

The ECD of glycoprotein hormone receptors is capable of high-affinity hormone binding (Xie et al. 1990, Braun et al. 1991, Moyle et al. 1994, Bhowmick et al. 1996, Thomas et al. 1996, Phang et al. 1998, Hong et al. 1999a,b, Ascoli et al. 2002, Smits et al. 2003, Vassart et al. 2004, Fan \& Hendrickson 2005), whereas $G$ protein activation and signal propagation is mediated by the heptahelical TMD (Ascoli et al. 2002, Vassart et al. 2004). However, both domains cooperate in intramolecular signal transmission. Thus, the concept has been put forward that the ECD of the TSHR acts as an inverse agonist to constrain the TMD in an inactive conformation (Zhang et al. 1995, 2000, Van Sande et al. 1996, Gruters et al. 1998, Nakabayashi et al. 2000, Nishi et al. 2002, VlaeminckGuillem et al. 2002). To investigate whether this is also the case for the human LHR, a receptor mutant (V2LHR) lacking the complete ECD was examined (Table 1; Sangkuhl et al. 2002). To achieve sufficient cell surface expression of this mutant, the first 39 amino acid residues of the human $\mathrm{V}_{2} \mathrm{R}$ were $\mathrm{N}$-terminally fused to the TMD. Additionally, to test whether the 'hinge region', the TMD-proximal part of the LHR-ECD, is essential for receptor activation, we created a mutant (V2hingeLHR) lacking the N-terminal part of the ECD but retaining the 'hinge region', to which the aforementioned $\mathrm{V}_{2} \mathrm{R}$ tag was added (Table 1). A HA-tag was inserted into the truncated mutants and the wild type receptor to allow for immunological detection of the receptor proteins (see Materials and methods).

First, we tested the protein expression of the wild type receptor (LHR wt) and the V2LHR mutant in COS-7 cells transfected with the appropriate cDNA using western blot analysis. Total membrane preparations derived from COS-7 cells expressing LHR wt or V2LHR revealed bands of 85 or $40 \mathrm{kDa}$ respectively, which did not appear in membrane fractions of non-transfected or mocktransfected cells indicating the specific detection of the glycosylated form of both proteins with the expected molecular mass (Fig. 1A; Ascoli et al. 2002). Tunicamycin treatment of cells expressing the wild type LHR or V2LHR reduced the apparent molecular mass to the expected size of both non-glycosylated proteins (LHR wt: $68 \mathrm{kDa}$ vs V2LHR: $38 \mathrm{kDa}$ ) indicating inhibition of N-linked glycosylation. In addition, high molecular weight bands were detected in COS-7 cells expressing the V2LHR mutant, which most probably represent oligomers of this receptor. Identification of the glycosylated form of V2LHR suggests that this truncated protein undergoes protein maturation in COS-7 cells as well as the wild type LHR. To investigate proper targeting of V2LHR to the plasma membrane, we performed immunofluorescence microscopy experiments with intact COS-7 cells expressing the wild type LHR or V2LHR. In both cases, cell surface expression was detected (Fig. 2), indicating correct targeting of the V2LHR variant to the plasma membrane. To quantify plasma membrane expression of V2LHR and V2hingeLHR, ELISA experiments were performed. These analyses revealed that cell surface expression of V2LHR and V2hingeLHR was similar to that of the wild type LHR (Fig. 1B). These data show that both truncated LHR are expressed in COS-7 cells and that a detectable amount of receptors is translocated to the plasma membrane.

To explore the role of the LHR-ECD on basal receptor activity, we investigated the signal transduction properties via the adenylyl cyclase pathway. To this end, we determined agonist-independent cAMP accumulation in COS-7 cells expressing LHR wt, V2LHR or V2hingeLHR. Since intracellular cAMP accumulation depends both on basal receptor activity and the amount of functional receptors targeted to the plasma membrane, we determined specific receptor activities (SRA), which were defined as the ratio of the receptor-dependent cAMP accumulation and the corresponding cell surface expression level. The wild type LHR exhibited an SRA of $12 \cdot 2 \pm 3 \cdot 2$ (Fig. 1D). Surprisingly, the SRA of both truncated receptors was not increased compared with the wild type value. In fact, the SRA of V2LHR $(8 \cdot 3 \pm 1 \cdot 9)$ was decreased by $32 \%$ compared with the wild type SRA. In addition, V2hingeLHR revealed an SRA $(6 \cdot 1 \pm 1 \cdot 0)$, which was reduced by $50 \%$ compared with the wild type value. These findings indicate that removal of the ECD does not enhance basal LHR activity, and thus, that the ECD in the case of the LHR does not serve as a tethered inverse agonist. These results are in line with previous studies (Sangkuhl et al. 2002, Karges et al. 2005) and in clear contrast to the model proposed for the TSHR (Zhang et al. 1995, 2000, Van Sande et al. 1996, Gruters et al. 1998, Nakabayashi et al. 2000, Nishi et al. 2002, Vlaeminck-Guillem et al. 2002). The absence of the ECD in V2LHR or the partial deletion of the ECD in V2hingeLHR reduced basal receptor activity, suggesting a putative role of the ECD as a positive, but not as a negative regulator of receptor activity. 

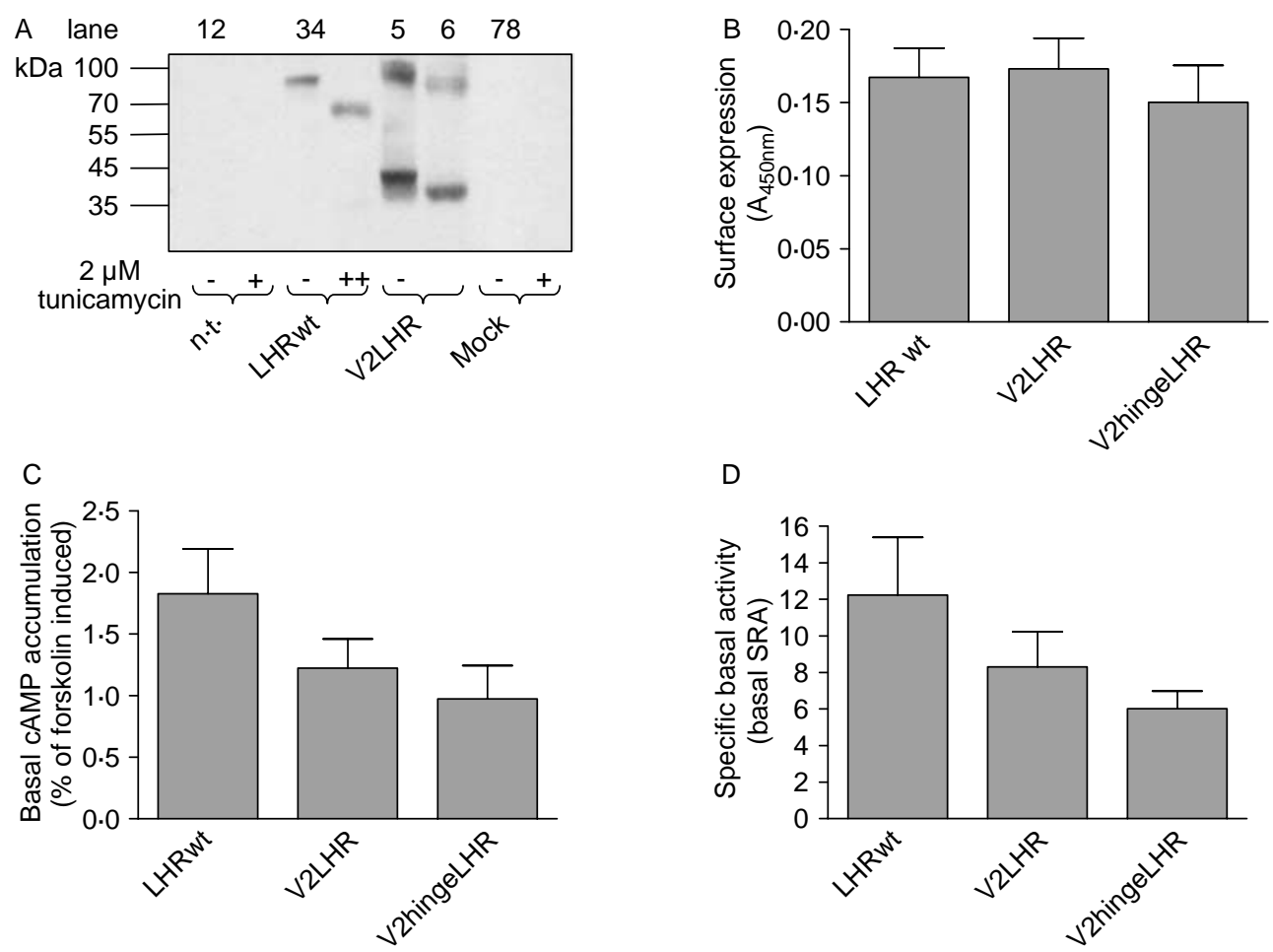

D
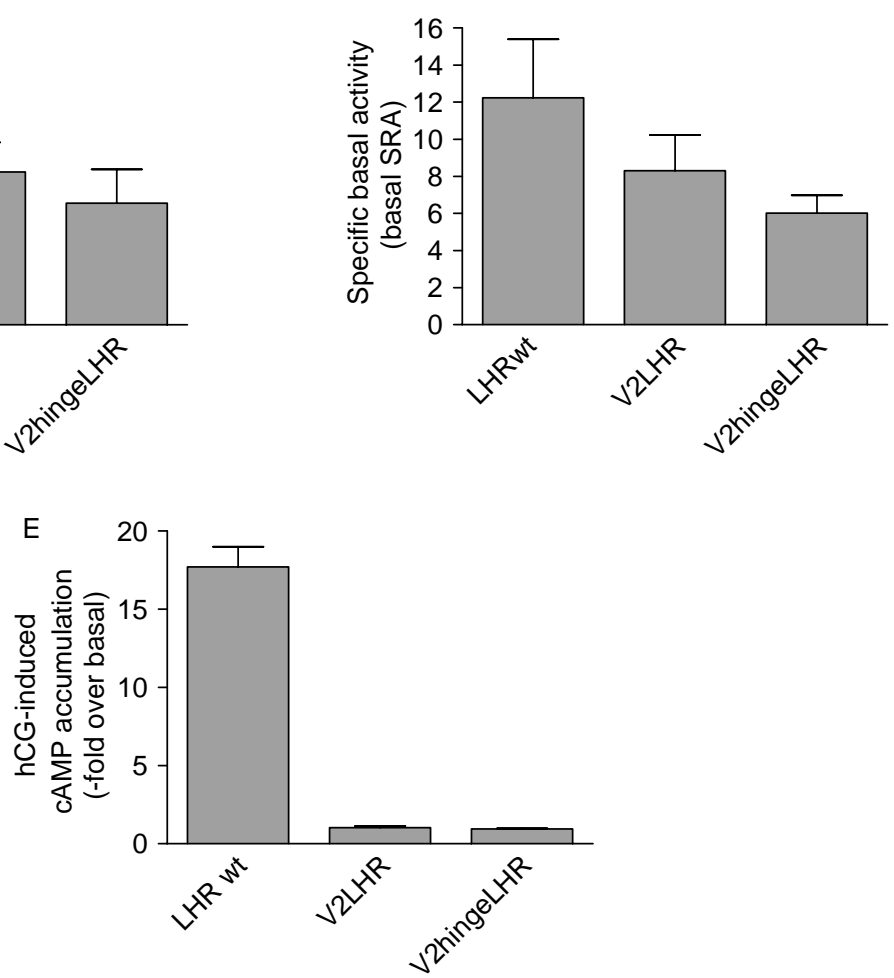

Figure 1 To examine expression and specific basal cAMP accumulation of wild type and N-terminally truncated LHR, receptors were expressed in COS-7 cells, and Western blot analyses (A) as well as cell surface ELISA (B) together with cAMP accumulation assays $(C)$ were performed as described under Materials and methods. $(A)$ For immunological detection of receptor proteins in membrane preparations, an HRP-labeled anti-HA antibody was used in Western blot analyses. (B) Plasma membrane targeting of receptors was quantified in ELISA experiments by using an antibody system against the HA-tag of the receptors. Cell surface expressions are presented as means \pm S.E. of $A_{450 \mathrm{~nm}}$ readings of two to five independent experiments, each carried out in quadruplicate. (C) Basal cAMP accumulations determined concomitantly to ELISA readings are presented as percentage of the cAMP level of cells derived from the same transfection after treatment with $100 \mu \mathrm{M}$ forskolin. Data are depicted as means \pm s.E. of two to five independent experiments, each carried out in triplicate. (D) Specific receptor activity (SRA) of each variant was determined by normalizing basal cAMP levels to cell surface expression. To this end, cAMP levels were divided by the receptor-dependent signal of $A_{450} \mathrm{~nm}$ readings in cell surface ELISA. Data are presented as means \pm S.E. (E) hCG-induced CAMP accumulations in COS-7 cells expressing truncated or the wild type LHR are expressed as -fold over basal cAMP production. Data are presented as the mean \pm S.E. of at least three independent experiments, each carried out in duplicate. 

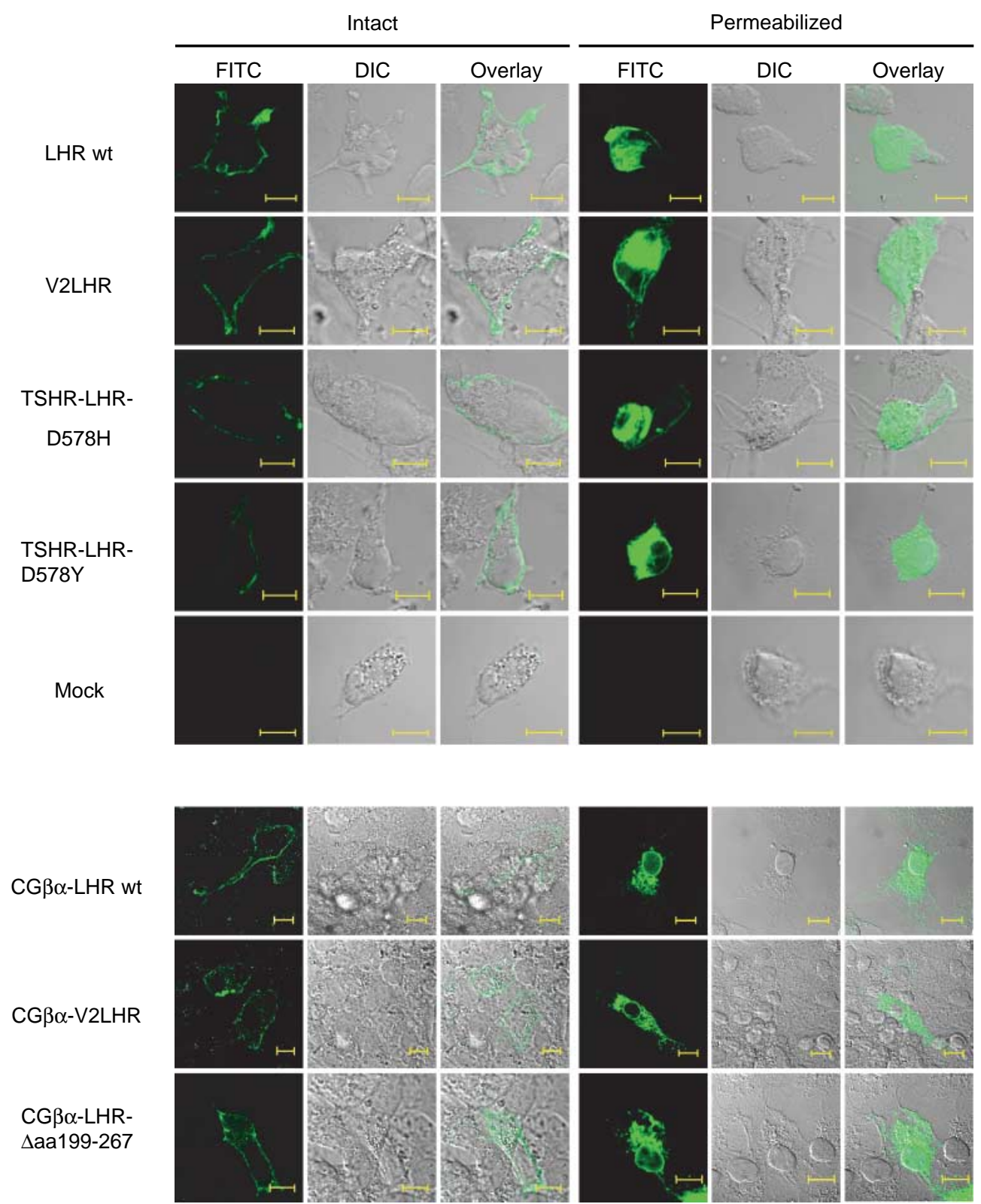

Figure 2 To examine subcellular localization of heterolous expressed wild type and mutant LHR, COS-7 cells were grown on glass cover slips and transfected with wild type or mutant LHR cDNA. After $48 \mathrm{~h}$, immunofluorescence studies were performed as described under Materials and methods. Intact and permeabilized cells were incubated with a monoclonal rat anti-HA antibody, and then probed with a fluorescein isothiocyanate-labeled anti-rat secondary antibody. In contrast, cells expressing receptors linked to $C G \beta \alpha$ were incubated with a rabbit anti-CG $\beta$ antiserum and then probed with a fluorescein isothiocyanate-labeled anti-rabbit secondary antibody. Images of fluorescein isothiocyanate fluorescence (FITC), the corresponding differential interference contrast images (DIC), and overlays of both are depicted (scale bars, $10 \mu \mathrm{m})$. Each picture is a typical representative of two independent experiments.

\section{An intact ectodomain is required for ligand-dependent receptor activation}

In cAMP accumulation assays hCG treatment of cells expressing the wild type LHR resulted in a $17 \cdot 6$-fold elevated cAMP level compared with the basal cAMP value (Fig. 1E). In contrast, none of the truncated receptors (V2LHR or V2hingeLHR) responded to hCG with cAMP increase. To exclude the possibility that the lack of agonist-dependent activation of truncated LHR was caused by low agonist affinity due to a missing hormone binding domain, fusion proteins between a 
single-chain variant of hCG (CG $\beta \alpha)$ and the full-length LHR (CG $\beta \alpha$-LHR wt) or truncated receptor variants (CG $\beta \alpha-V 2 L H R$ and CG $\beta \alpha-V 2 h i n g e L H R)$ were constructed (Table 1). In a previous study it has been shown that this single-chain hCG activates the LHR as efficiently as the native hormone (Sugahara et al. 1995). To avoid sterical hindrance within the CG $\beta \alpha$-V2LHR fusion protein in which the single-chain hCG might be fixed in a rigid position that forestalls productive interaction with the TMD, we introduced a linker sequence between tethered CG $\beta \alpha$ and the LHR-TMD by inserting the major portion of the ECD (amino acid residues 108-404) of the distantly related relaxin receptor LGR7 (CG $\beta \alpha-$ V2GR7LHR) (Table 1).

First, we examined protein expression of hormonereceptor variants by Western blot analysis (Fig. 3A). Membrane preparations of cells transfected with CG $\beta \alpha$ LHR wt cDNA contained a protein with an apparent molecular mass of $115 \mathrm{kDa}$ (Fig. 3A, lane 1). An additional high-molecular mass protein (around 200$250 \mathrm{kDa}$ ) of unknown composition was also discernible (lane 1). Analysis of membrane preparations obtained from cells expressing CG $\beta \alpha$-V2LHR revealed a specific band with an expected molecular mass of $70 \mathrm{kDa}$ and an additional broad band of about $160 \mathrm{kDa}$ (lane 2). The high-molecular mass proteins might represent oligomeric forms of the hormone-receptor fusion proteins. To visualize plasma membrane targeting of hormone-receptor chimeras, immunofluorescence experiments were performed with an antiserum raised against the $\beta$-subunit of hCG. In these analyses, CG $\beta \alpha$ LHR wt and CG $\beta \alpha$-V2LHR were detected at the cell surface of COS-7 cells (Fig. 2). ELISA experiments revealed that truncated LHR fused to CG $\beta \alpha$ were expressed at the cell surface to $68-81 \%$ of the CG $\beta \alpha$ LHR wt expression (Fig. 3B).

To examine hCG-promoted signaling properties of CG $\beta \alpha$-LHR wt compared with the unmodified wild type receptor, concentration-response curves of cAMP accumulation were determined (Fig. 3C). In these analyses, hCG activated the wild type LHR with an $\mathrm{EC}_{50}$ value of $2 \cdot 0 \mathrm{nM} \pm 0 \cdot 2$, whereas in the case of CG $\beta \alpha$-LHR wt, the half-maximally effective agonist concentration was shifted towards higher concentrations by a factor of 47 $\left(\mathrm{EC}_{50}=93 \mathrm{nM} \pm 0 \cdot 2\right)$, most likely reflecting steric hindrance imparted by the fused single-chain gonadotropin. These data are in clear contrast to previous studies (Narayan et al. 2000, 2002) showing that a similar fusion protein between the hCG and the LHR connected via a flexible linker containing the CTP region of the hCG is not further activated by endogenous hCG. Thus, we generated two additional hCG-LHR fusion proteins: one harboring the CTP region of the hCG between the CG $\beta \alpha$ and the LHR wt (CG $\beta \alpha$-CTP-LHR wt) and a second one lacking again the entire ECD of the LHR (CG $\beta \alpha$-CTPV2LHR; Table 1). Surprisingly, both constructs showed a significant increase in cell surface expression when compared with the hormone wild type LHR variant without the CTP (CG $\beta \alpha$-LHR wt; Fig. 3B). In terms of SRA, CG $\beta \alpha$-LHR wt $(2 \cdot 6 \pm 0 \cdot 2)$ and CG $\beta \alpha$-CTP-LHR wt $(3 \cdot 8 \pm 0 \cdot 4)$ clearly exhibited high basal SRA (Fig. 3E) when compared with the LHR wt. Interestingly, in line with the previous studies (Narayan et al. 2000, 2002), for the CG $\beta \alpha$-CTP-LHR wt fusion protein no further increase in cAMP production was observed after adding exogenous hCG. Thus, these constructs allowed us to examine the consequences of ECD truncation or deletion for receptor activity in the presence of a tethered agonist. All constructs lacking the ECD of the LHR: CG $\beta \alpha$-V2LHR (SRA: $1 \cdot 0 \pm 0 \cdot 1$ ), CG $\beta \alpha$-V2hingeLHR (SRA: $1 \cdot 1 \pm 0 \cdot 1$ ), CG $\beta \alpha$-V2LGR7LHR (SRA: $1 \cdot 2 \pm 0 \cdot 1$ ) and CG $\beta \alpha-C T P-$ V2LHR (SRA: $0 \cdot 4 \pm 0 \cdot 02$ ) did not show an increased SRA under basal conditions, clearly indicating that an intact LHR-ECD is required for ligand-dependent receptor activation and that the hormone per se is unable to activate the TMD.

\section{Deletion of LRR leads to a loss of function of hormone-receptor fusion proteins}

A prominent structural feature of the ECD of the LHR and related glycoprotein hormone receptors is the presence of ten LRR (Fan \& Hendrickson 2005). There

Figure 3 Fusion proteins between single-chain hCG and wild type or truncated receptors were expressed in COS-7 cells, and Western blot analyses (A) as well as ELISA experiments (B) and cAMP accumulation assays (C and D) were performed as described under Materials and methods. (A) To detect hormone-receptor variants in membrane preparations, Western blots were incubated with a rabbit anti-CG $\beta$ antiserum and thereafter with an HRP-labeled anti-rabbit antibody. (B) Cell surface expression of hormone-receptor mutants was quantified in ELISA assays and compared with the plasma membrane targeting signal of CG $\beta \alpha$-LHR wt. Receptors were detected by using a rabbit anti-CG $\beta$ antiserum and an HRP-labeled anti-rabbit secondary antibody. Data are presented as means \pm s.E. of $A_{450} \mathrm{~nm}$ readings of least three independent experiments, each carried out in triplicate. (C) hCG-stimulated cAMP accumulation in COS-7 cells expressing CG $\beta \alpha$-LHR wt or the wild type LHR was determined. cAMP formation is expressed as -fold over basal cAMP production of the wild type LHR. Representative concentration-response curves of five independent experiments, each carried out in duplicate, are shown. (D) Basal and agonist-induced cAMP formation of hormone-receptor proteins are expressed as -fold over basal cAMP production of the wild type LHR. Data are presented as means \pm s.E. of two to twelve independent experiments, each carried out in duplicate or triplicate. Dashed line indicates basal cAMP value of the wild type LHR. (E) Specific receptor activity (SRA) of each variant was determined by normalizing basal and agonist-induced cAMP levels to cell surface expression. To this end, cAMP levels (D) were normalized to the cell surface expression of each construct (B), whereas the ELISA signal $\left(A_{450 \mathrm{~nm}}\right)$ of CG $\beta \alpha$-LHR wt was arbitrarily set to 1. Data are depicted as means \pm S.E. 
is ample experimental evidence to suggest that the $\mathrm{N}$-terminal LRR are required for hormone binding (Braun et al. 1991, Bhowmick et al. 1996, Thomas et al. 1996, Hong et al. 1998, Ascoli et al. 2002, Fan \& Hendrickson 2005), whereas the effect of the
C-terminal LRR on hCG binding affinity remained controversial (Braun et al. 1991, Thomas et al. 1996, Hong et al. 1998, Ascoli et al. 2002, Fan \& Hendrickson 2005). Thus, we sought to define the role of the C-terminal LRR, i.e. LRR 8-10 according to Fan and
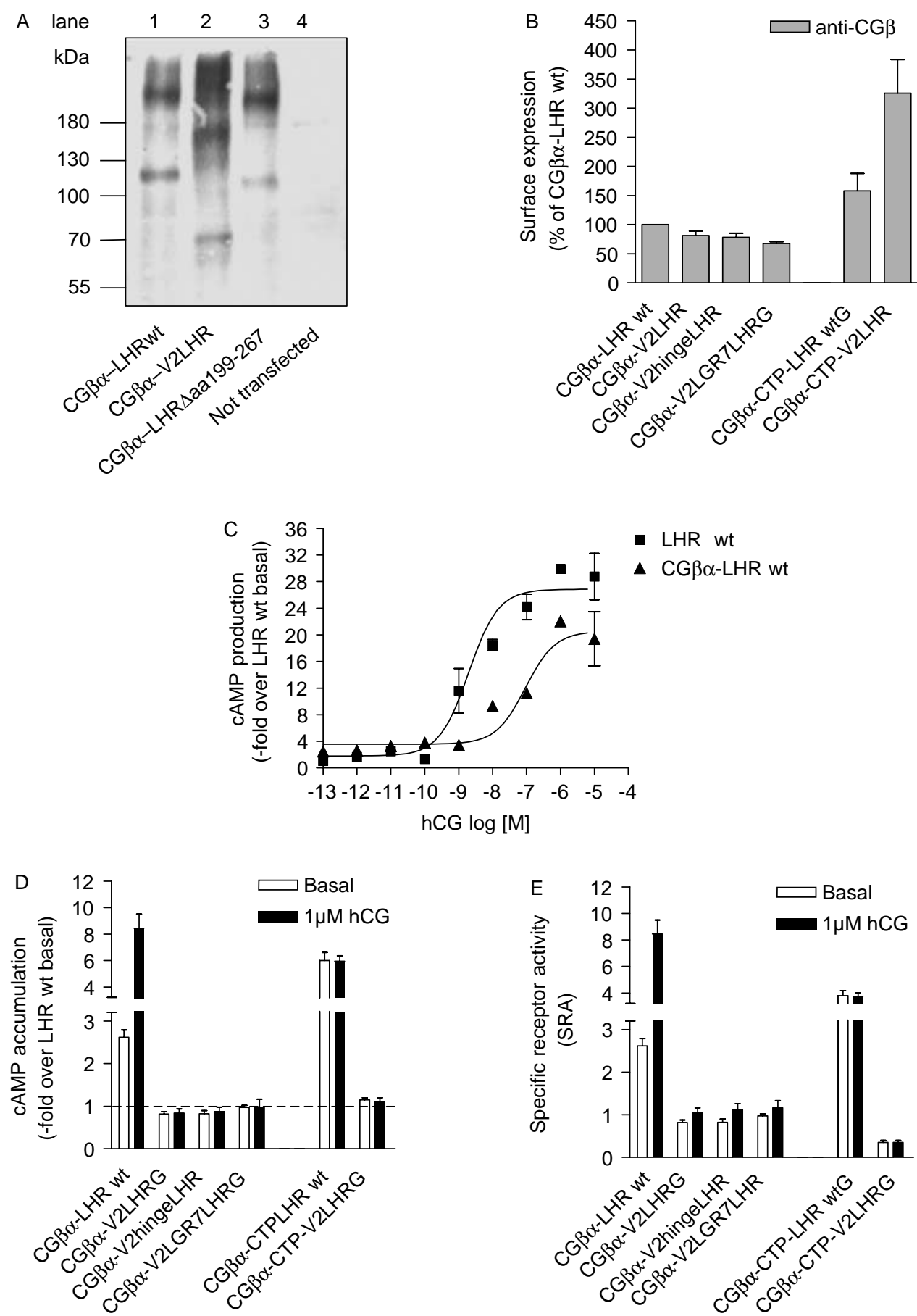
colleagues, (Fan \& Hendrickson 2005), in the regulation of LHR activity. Truncated LHR mutants in which discrete LRR were deleted have been shown to be retained intracellularly and could therefore not be studied functionally (Thomas et al. 1996). To avoid this problem, we deleted amino acid residues from 199 to 267 (LRR 8-10) within the fusion protein consisting of
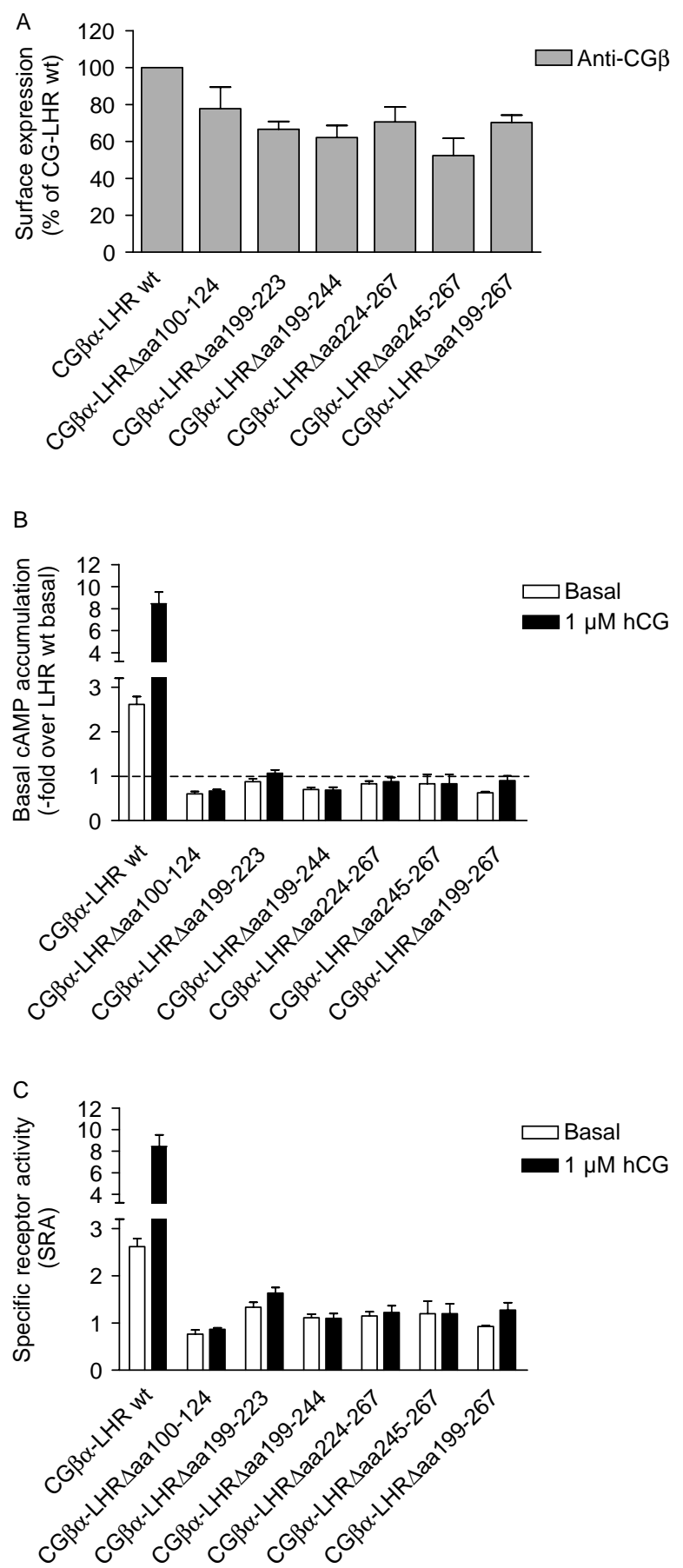

hCG and the wild type LHR (CG $\beta \alpha$-LHR $\Delta$ aa199-267) to promote cell surface expression of these LHR 8-10 deficient receptor mutants. Thus, our aim was to identify putative structures within LRR $8-10$ crucial for the formation of active receptor states (Table 1).

ELISA experiments revealed that CG $\beta \alpha$-LHR $\Delta$ aa 199 267 was expressed at the cell surface to about $70 \%$ of the expression level of CG $\beta \alpha$-LHR wt (Fig. 4A). Immunofluorescence stainings of CG $\beta \alpha$-LHR $\Delta$ aa199-267 (Fig. 2) confirmed surface ELISA data indicating efficient membrane trafficking. Furthermore, membrane fractions of COS-7 cells expressing CG $\beta \alpha-$ LHR $\Delta$ aa199-267 were subjected to Western blot analysis and compared with membrane preparations of COS-7 cells transfected with CG $\beta \alpha$-LHR wt or CG $\beta \alpha$-V2LHR cDNA (Fig. 3A). A specific band with an apparent molecular mass of $110 \mathrm{kDa}$ was detected in cells expressing CG $\beta \alpha$-LHR $\Delta$ aa199-267 (Fig. 3A, lane 3) commensurate with the estimated molecular mass. Additionally, a diffuse band in the high-molecular weight range $(>180 \mathrm{kDa})$ was detected, most probably representing an oligomeric cluster of the receptor. In contrast, to CG $\beta \alpha$-LHR wt, CG $\beta \alpha$-LHR $\Delta$ aa199-267 expressed in COS-7 cells did not exhibit an increased basal or agonist-induced SRA (Fig. 4C). This result was compatible with our earlier hypothesis, and we assumed at this stage that the lack of cAMP responsiveness was due to a missing agonistic structure located in the C-terminal LRR (LRR 8-10). By deleting various portions of the region between amino acid residues 199 and 267, we sought to further narrow down a potential endogenous agonistic structure or a structure contributing to agonistpromoted receptor activity respectively (Table 1 ).

To point out possible functional differences between the N-terminal LRR (e.g. LRR 3) and the C-terminal LRR (LRR 8-10), we generated an additional mutant hormone-receptor protein lacking amino acids from 100 to 124 within LRR 3 (CG $\beta \alpha$-LHR $\Delta$ aa100-124), which is thought to participate in hormone binding

Figure 4 Various LRR were deleted from single-chain hCG/LHR constructs, and the resulting mutants were expressed in COS-7 cells. (A) Cell surface expression of hormone-receptor mutants was quantified in ELISA assays and compared with the plasma membrane targeting signal of CG $\beta \alpha$-LHR wt. Receptors were detected by using a rabbit anti-CG $\beta$ antiserum and an HRPlabeled anti-rabbit secondary antibody. Data are presented as means \pm s.E. of $A_{450 \mathrm{~nm}}$ readings of least three independent experiments, each carried out in triplicate. (B) Basal and agonistdependent CAMP accumulations were as well determined. CAMP levels are expressed as -fold over basal cAMP production of the wild type LHR. Data are presented as means \pm S.E. of at least three independent experiments, each carried out in duplicate. Dashed line indicates the basal cAMP level of the wild type LHR. (C) Specific basal and agonist-dependent receptor activity of each variant was determined by normalizing basal and agonist-induced cAMP levels to cell surface expression. cAMP levels were divided by the receptor-dependent signal of $A_{450 \mathrm{~nm}}$ readings in cell surface ELISA, whereas the signal of $A_{450 \mathrm{~nm}}$ readings of CG $\beta \alpha$ LHR wt was arbitrarily set to 1 . Data are depicted as means \pm S.E. 
(Thomas et al. 1996, Ascoli et al. 2002, Fan \& Hendrickson 2005). However, deletion of LRR 3 hampered the tethered agonist to activate the receptor, as indicated by the low basal SRA levels observed for the CG $\beta \alpha$-LHR $\Delta$ aa100-124 mutant (Fig. 4C). These data indicate that deletions in the N-terminal or C-terminal region of the LRR lead to a misfolded ECD, which is not able to stabilize an active receptor conformation. Further, no continuous linear agonistic structure in the $\mathrm{C}$-terminal LRR region could be defined suggesting that the integrity of the ECD is required for agonistinduced receptor activation.

\section{The ectodomain stabilizes an activation-competent receptor conformation}

Removal of the ECD from the TMD of the LHR led to a slightly decreased basal receptor activity compared with the full-length receptor. Unfortunately, basal activity of the LHR is rather low compared with other GPCR. Therefore, we took advantage of naturally occurring activating point mutations of the LHR that result in dramatically increased agonist-independent receptor activity of the wild type LHR (Laue et al. 1995, Yano et al. 1996, Latronico et al. 1998, Muller et al. 1998, Kremer et al. 1999, Liu et al. 1999). Four different point mutations (L457R in TMD-3, D564G in IL-3, D578H and D578Y in TMD-6; details in Table 1) were integrated into V2LHR, and these mutants were compared with their full-length LHR counterparts.

In line with previous reports (Laue et al. 1995, Yano et al. 1996, Latronico et al. 1998, Muller et al. 1998, Kremer et al. 1999, Liu et al. 1999), all mutations inserted into the full-length LHR resulted in significantly increased basal SRA $(6 \cdot 7-44 \cdot 1)$ as compared with the SRA of the wild type without any mutation (Fig. 5C). In contrast, only one mutation $(\mathrm{D} 578 \mathrm{H})$ evoked high agonist-independent SRA in the absence of the ECD (V2LHR-D578H: SRA = $9 \cdot 9 \pm 0 \cdot 5)$. After deletion of the ECD, the effect of the mutations L457R, D564G and D578Y on receptor activity was dramatically reduced as compared with their effect in the wild type receptor. The basal SRA of the truncated LHR harboring the L457R-mutation was decreased to $47 \% \pm 3 \cdot 4$ of the SRA of the wild type LHR containing the same mutation. Furthermore, V2LHR-D564G and V2LHR-D578Y exhibited a basal SRA of $6 \cdot 3 \% \pm 0 \cdot 7$ or $22.4 \% \pm 1.5$ of the SRA value of their wild type counterparts harboring the same mutation respectively. The data observed for the D578H-mutation suggest that ECD-deficient LHR principally have the potential to activate the $G_{\mathrm{s}}$ pathway and are not inactive per se. However, these receptors cannot be mutationally activated as efficiently as the wild type LHR. The ECD may be necessary to stabilize a distinct conformation of the heptahelical portion, prone to be rendered constitutively active by missense mutations. Since this hypothesis is in clear contrast to the model proposed for the closely related TSHR, we questioned whether the TSHR-ECD would render the LHR-TMD activation-competent for heptahelical activating mutations in the same way as the native LHR-ECD or whether it would act as a tethered inverse agonist on the LHR-TMD as observed for the wild type TSHR. Therefore, we attached the TSHR-ECD (amino acid residues 1-413) to the truncated LHR harboring the above mentioned activating point mutations (Table 1). Two of these resulting TSHR-LHR chimeras (TSHR-LHR-D578H and TSHR-LHR-D578Y) were tested in immunofluorescence studies, and both mutants were detected on the cell surface (Fig. 2).

As reported earlier, analogous TSHR-LHR chimeras are able to bind TSH and can be stimulated by TSH (Braun et al. 1991). Indeed, in our hands all TSHR-LHR constructs responded to $100 \mathrm{mU} / \mathrm{ml}$ bTSH with a 4- to 11-fold increase in cAMP formation as compared with the basal cAMP value of the wild type LHR (Fig. 5B). Interestingly, TSHR-LHR chimeras harboring activating TMD-mutations showed significantly reduced basal SRA as compared with their wild type LHR counterparts (Fig. 5C). However, SRA of TSHR-LHR constructs were slightly higher than those of the V2LHR variants. Solely, the D578H-mutation inserted into the TSHR-LHR sequence induced strong constitutive receptor activity. To summarize, the propensity of three out of four activating TMD-mutations to induce high basal receptor activity was dramatically reduced in the absence of the LHR-ECD. Furthermore, the TSHR-ECD was not fully sufficient to render the LHR serpentine domain activation-competent for activating mutations, and therefore could not functionally replace the LHR-ECD.

To address the question whether an intact LHR-ECD would be necessary to facilitate the formation of active receptor states induced by agonist action or activating mutations, several naturally occurring activating mutations located within the sixth $\alpha$-helical membrane-spanning domain (D564G, D578H, D578Y) were introduced into two LRR-deletion variants of the CG-receptor fusion protein (CG $\beta \alpha$-LHR $\Delta$ aa199-223 and CG $\beta \alpha$-LHR $\Delta$ aa199-244) and CG $\beta \alpha$-LHR wt (Table 1). CG $\beta \alpha$-LHR wt constructs comprising TMDmutations exhibited SRA of $1 \cdot 8-5 \cdot 7$. However, LRRdeletion mutants harboring TMD-mutations revealed significantly decreased SRA compared with their CG $\beta \alpha$ LHR wt counterparts (Fig. 6C), indicating that deletions in the LRR result in a misfolded ECD and thus abolish the ability of the ECD to support the action of activating mutations.

Taken together, these data support the overall concept that the ECD contributes to the formation of an active receptor state and that it facilitates agonist action and the properties of naturally occurring activating mutations. 

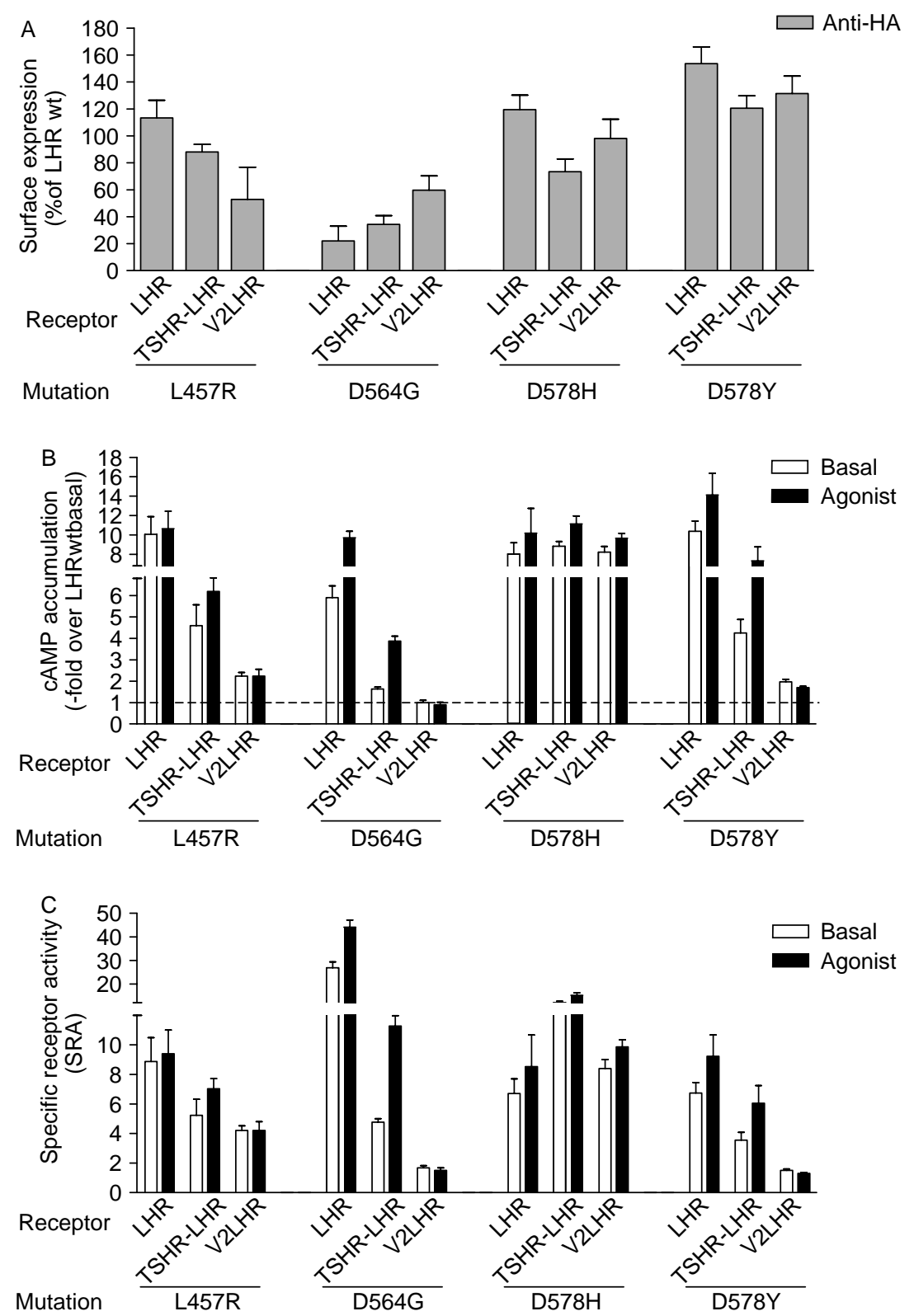

Figure 5 Several N-terminally modified LHR mutants containing the naturally occurring activating mutations L457R, D564G, D578H or D578Y were constructed and analyzed concerning specific receptor activity as described under Materials and methods. To determine specific receptor activities (C), plasma membrane targeting (A) as well as basal and agonist-induced cAMP accumulation (B) were examined. (A) Cell surface expression of hormone-receptor mutants was quantified in ELISA experiments and compared with the plasma membrane targeting signal of the wild type LHR. Receptors were detected by using an antibody system against the HA-tag of the receptors. Data are presented as means \pm s.E. of $A_{450 \mathrm{~nm}}$ readings of at least three independent experiments, each carried out in triplicate. (B) In cAMP accumulation assays, cells expressing receptor variants of LHR or V2LHR structure were incubated with or without $1 \mu \mathrm{M} \mathrm{hCG}$, whereas cells expressing TSHR-LHR chimeras were treated with or without $100 \mathrm{mU} / \mathrm{ml} \mathrm{bTSH}$. Basal and agonist-induced cAMP values are expressed as -fold over basal CAMP production of the wild type LHR. Data are depicted as means \pm S.E. of at least three independent experiments, each carried out in duplicate. (C) Specific basal and agonist-dependent receptor activities (SRA) of each variant were determined by normalizing basal and agonist-induced cAMP levels to cell surface expression. cAMP levels were divided by the receptor-dependent signal of $A_{450 \mathrm{~nm}}$ readings in cell surface ELISA, whereas the signal of $A_{450 \mathrm{~nm}}$ readings of LHR wt was arbitrarily set to 1 . Data are depicted as means \pm S.E. 

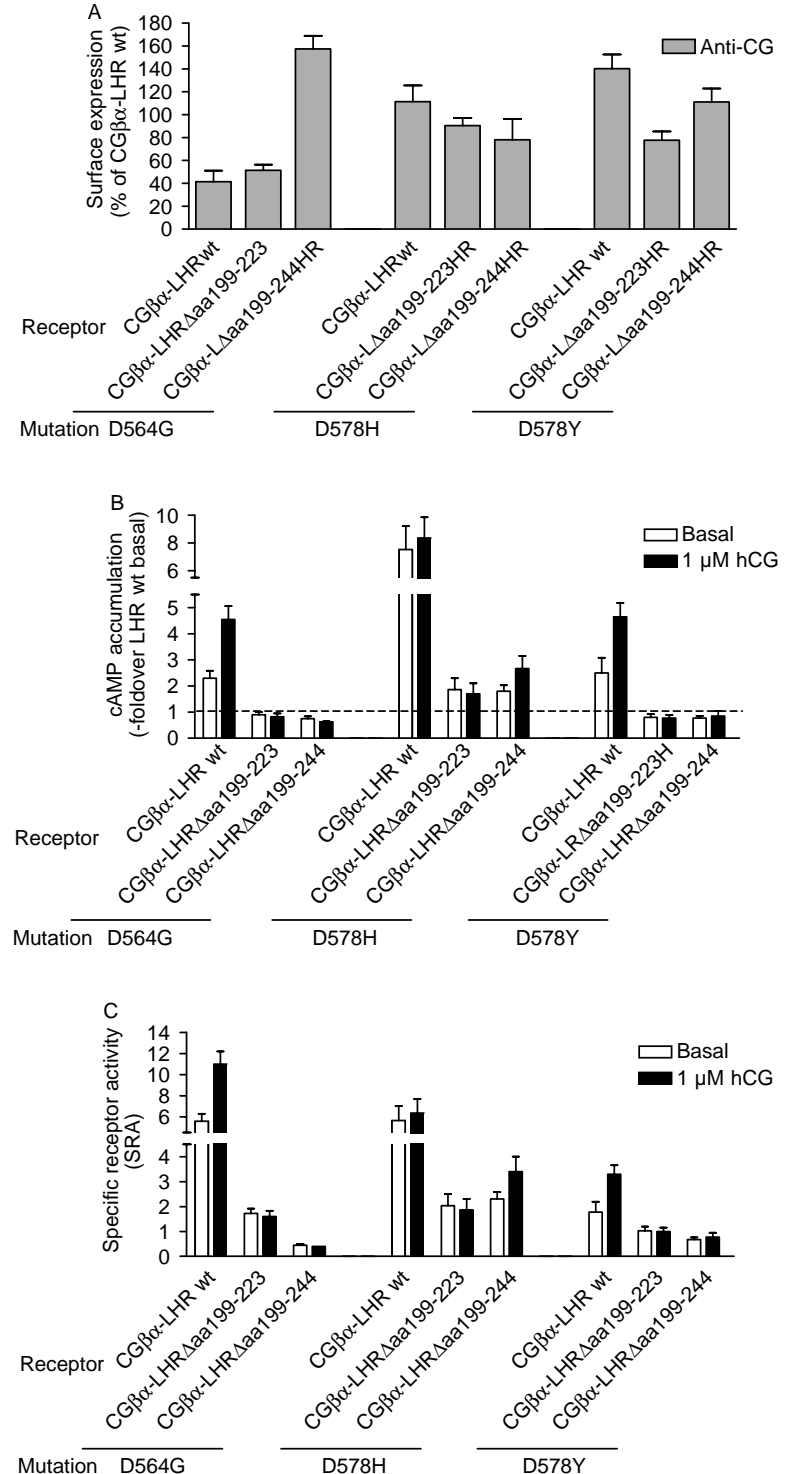

Figure 6 Various LRR were deleted from single-chain hCG/LHR constructs containing naturally occurring activating TMD-mutations, and the resulting mutants were expressed in COS-7 cells. (A) Cell surface expression of mutant receptors was quantified in ELISA experiments and compared with the plasma membrane targeting signal of CG $\beta \alpha$-LHR wt. Receptors were detected by using a rabbit anti-CG $\beta$ antiserum and an HRP-labeled anti-rabbit secondary antibody. Data are presented as means \pm S.E. of $A_{450 \mathrm{~nm}}$ readings of two to three independent experiments, each carried out in triplicate. (B) Basal and agonist-dependent cAMP accumulations were determined. CAMP levels are expressed as -fold over basal cAMP production of the wild type LHR. Data are presented as means \pm S.E. of two to three independent experiments, each carried out in duplicate. Dashed line indicates the basal cAMP level of the wild type LHR. (C) Specific basal and agonist-dependent receptor activity of each variant was determined by normalizing basal and agonistinduced cAMP levels to cell surface expression. cAMP levels were divided by the receptor-dependent signal of $A_{450 \mathrm{~nm}}$ readings in cell surface ELISA, whereas the signal of $A_{450} \mathrm{~nm}$ readings of CG $\beta \alpha$-LHR wt was arbitrarily set to 1 . Data are depicted as means \pm S.E.

\section{Discussion}

A detailed understanding of the mechanism of glycoprotein hormone receptor activation is helpful for the development of new pharmacological tools for therapeutic intervention. Principle aspects of glycoprotein hormone receptor activation have been thoroughly investigated over the past years, but the exact mechanism is still a moot issue. Our data provide evidence for the contribution of the ECD of the LHR to adenylyl cyclase activation induced by agonist or activating point mutations suggesting that the ECD stabilizes a receptor conformation prone to be activated by naturally occurring mutations or the cognate agonist. In this context, the integrity of the ECD, particularly the intactness of the LRR domain is a prerequisite for the ability of the LHR-ECD to stabilize an activation-competent receptor conformation. The ECD of the closely related TSHR is not fully sufficient to render the LHR-TMD susceptible to activating mutations. Thus, the function of the ECD may differ between the glycoprotein hormone receptors. To summarize, our findings highlight an as yet unappreciated role of the ECD pertinent to LHR activation by agonist and by naturally occurring mutations.

\section{LHR ectodomain does not serve as an endogenous inverse agonist}

Due to observations made in the TSHR, several studies support an activation model in which the ECD of glycoprotein hormone receptors functions as a tethered inverse agonist constraining the receptor in an inactive state (Zhang et al. 1995, 2000, Van Sande et al. 1996, Gruters et al. 1998, Nakabayashi et al. 2000, Nishi et al. 2002, Vlaeminck-Guillem et al. 2002). This hypothesis is corroborated by findings that gentle treatment of cells expressing the TSHR with trypsin results in agonist-independent receptor activation (Van Sande et al. 1996). In contrast, we report here for the LHR that removal or partial deletion of the ECD by genetic engineering does not result in any detectable increase in basal LHR activity. In fact, deletion of the ECD tended to reduce LHR activity, indicating a specific and distinct role of the ECD among the different glycoprotein hormone receptors. The observation that removal of the LHR-ECD does not induce constitutive receptor activity is further supported by recent observations that cAMP production of the wild type LHR after chemical shedding of the ECD from the TMD remains at a low level (Karges et al. 2005). These findings are consistent with previous data (Sangkuhl et al. 2002, Karges et al. 2005) and thus, the role of the ECD for LHR activation appears to differ from the situation for the TSHR (Zhang et al. 1995, 2000, Van 
Sande et al. 1996, Gruters et al. 1998, Nakabayashi $e t$ al. 2000, Nishi et al. 2002, Vlaeminck-Guillem et al. 2002).

\section{An intact ectodomain is required for ligand-dependent receptor activation}

To exclude the possibility that the lack of agonistdependent activation of N-terminally truncated LHR was based upon extremely low agonist affinity due to a missing hormone-binding domain, several fusion proteins between single-chain hCG and LHR variants were generated and functionally analyzed. These hormone-receptor chimeras allowed us to study the influence of the complete ECD or parts of the ECD on receptor activity in the presence of the agonist, in our case a tethered agonist.

As expected from previous studies (Narayan et al. 2000, 2002), fusion of single-chain hCG to the fulllength LHR resulted in receptors with high constitutive activity. In contrast, none of the truncated receptor mutants fused to hCG (CG $\beta \alpha$-V2LHR, CG $\beta \alpha-V 2 h i n-$ geLHR, CG $\beta \alpha$-V2LGR7LHR and CG $\beta \alpha$-CTP-V2LHR) displayed constitutive or agonist-induced activity (Fig. 3E). At least two straightforward explanations may account for this observation: first, determinants in the ECD may be required to induce a conformational change in the ligand, a structural rearrangement that was shown to occur following binding of FSH to its hormone-binding domain (Fan \& Hendrickson 2005). These receptor-induced conformational changes in the loops of one or both subunits of the hormone as well as in the C-terminus of the common $\alpha$-subunit may be critical for TMD activation and may be absent in truncated variants (CG $\beta \alpha$-V2LHR, CG $\beta \alpha$-V2hingeLHR and CG $\beta \alpha$-CTP-V2LHR) lacking an LRR-containing hormone-binding domain. However, it should also be taken into consideration that single-chain glycoprotein hormone analogs apparently display remarkable conformational flexibility. Accordingly, 'multisubunit' variants harboring CG, FSH and TSH activity due to the combination of $\beta$-subunit domains are biologically active in vitro and in vivo (Garcia-Campayo et al. 2002, 2004, Ben-Menahem 2004). Secondly, the activation determinants for the TMD may be localized in the ligand and in the ECD or even in the ECD alone. Thus, in the absence of the N-terminal portion of the ECD, the LRR region or the 'hinge region', it may not be possible to elicit an adequate conformational change in the TMD allowing for productive coupling to $\mathrm{G}_{\mathrm{s}}$.

To test the possibility that the spacing between singlechain hormone and the receptor was insufficient in the truncated hormone-receptor fusion construct $(\mathrm{CG} \beta \alpha-$ V2LHR) thereby precluding activation of the serpentine domain, we integrated a long linker between the tethered hormone and the truncated LHR. The resulting construct CG $\beta \alpha$-V2LGR7LHR contained a linker which consisted of the major part of the ECD of hLGR7, a member of the LGR family (Hsu et al. 2000, 2002, Herpin et al. 2004). The ECD of hLGR7 is thought to attain a similar overall fold as gonadotropin receptor ECD, whereas the degree of primary sequence identity is low (Hsu et al. 2000). When analyzed functionally, CG $\beta \alpha$-V2LGR7LHR also failed to stimulate cAMP production, suggesting that an intact endogenous ECD is required for ligand-dependent receptor activation and that the hormone per se is unable to activate the TMD.

\section{No agonistic structure is identifiable within the LRR}

It is well established that the N-terminal part of the LRR domain is critical for ligand binding (Braun et al. 1991, Bhowmick et al. 1996, Thomas et al. 1996, Hong et al. 1998, Ascoli et al. 2002, Fan \& Hendrickson 2005). However, conflicting data on the contribution of the C-terminal part of the LRR domain to hormone binding have been published (Braun et al. 1991, Thomas et al. 1996, Hong et al. 1998, Ascoli et al. 2002, Fan \& Hendrickson 2005). We reasoned that if the C-terminal LRR are dispensable for hormone binding, they may harbor a structural module functioning as a tethered agonist for the TMD providing an explanation why fusion proteins between hCG and truncated receptors lacking these LRR are inactive. To circumvent the problem that N-terminally truncated LHR constructs are mainly trapped intracellularly (Thomas $e t a l$. 1996), we deleted various parts of the C-terminal LRR within the hormone-receptor fusion constructs to identify possible agonistic structures within the ECD of glycoprotein hormone receptors. The LRR-deletion mutants devised in our study were efficiently delivered to the cell surface as measured by ELISA with an antiserum against the $\beta$-subunit of hCG. This effect may be attributed to plasma membrane targeting mediated by the tethered hormone. Thus, functional characteristics of the different LRR-deletion mutants could be directly compared with the wild type LHR for the first time. Taking cAMP accumulation as readout, none of the deletion mutants revealed constitutive or agonistinduced receptor activity (Fig. 4C). Partial removal of LRR lead to a total loss of the elevated cAMP accumulation elicited by CG $\beta \alpha-L H R$ wt expression indicating that an intact ECD comprising all LRR is required for agonist-dependent receptor activation.

\section{The ectodomain stabilizes an activation-competent receptor conformation}

Contrary to other class A G protein-coupled receptors, hormone binding to the ECD occurs with high affinity in the absence of the TMD (Rapoport et al. 1998, 
Ascoli et al. 2002, Vassart et al. 2004). As G protein activation is mediated by the serpentine region, the intramolecular signal transduction between the ECD and the TMD represents a challenging mechanistic issue. Our understanding of the mechanisms involved in the activation of the LHR has been greatly advanced by investigations on naturally occurring mutations that cause constitutive activation of this receptor. Extensive mutagenesis studies with the LHR revealed that constitutive activity can arise both by the disruption of distinct interhelical contacts stabilizing an inactive receptor state and also by the formation of new interhelical bonds that foster an active state of the serpentine region (Ascoli et al. 2002).

In the context of our experiments, a key question relates to the issue whether or not the heptahelical portion of the receptor can be activated mutationally at all and is principally able to interact with $\mathrm{G}_{\mathrm{s}}$ independently of the ECD. To answer this question, several naturally occuring activating mutations were integrated into the wild type LHR and the LHR variant lacking the complete ECD (V2LHR). Comparison of wild type and truncated LHR harboring the same mutation revealed that in the case of three (L457R, D564G and D578Y) out of four mutations, basal receptor activity was dramatically decreased in the absence of the ECD (Fig. 5C), clearly indicating the importance of the ECD for the stabilization of an active receptor conformation. Only the D578H-mutation, which is located in TMD-6, gave rise to high basal cAMP levels via the truncated LHR (V2LHR) (Fig. 5C). This mutation has been identified in Leydig cell adenomas, and has been reported to induce strong agonist-independent receptor activity (Liu et al. 1999). Along these lines that only a mutation located in TMD-6 was potent enough to induce high constitutive activity in the truncated LHR, only activating mutations located in TMD-6 were found to constitutively activate an N-terminally truncated TSHR while single amino acid exchanges in extracellular loops were ineffective (Vlaeminck-Guillem et al. 2002). However, while both mutations engineered in TMD- 6 rendered the TSHR constitutively active, only one out of four activating mutations in the serpentine portion of the LHR entailed elevated agonist-independent cAMP production thus lending further credence to the notion that the TSHR-TMD is less constrained and more susceptible to mutational activation than the gonadotropin receptors (Cetani et al. 1996, Biebermann et al. 1998, Schulz et al. 1999).

Our results demonstrate that an intact ECD is an important module for efficient activation of the LHR by naturally occurring activating mutations and by agonist. An appealing model to explain these findings is to assume that the LHR-ECD stabilizes receptor conformations in which multiple distinct interhelical bonds promoting constitutive receptor activity are disrupted by mutations in the TMD. In accord with this notion, a salt bridge between defined amino acid residues has recently been shown to underlie constitutive LHR activity induced by the L457R-mutation (Zhang et al. 2005). Likewise, an aspartate side chain at position 578 functions as a properly positioned hydrogen bond acceptor to stabilize an inactive state of the LHR (Kosugi et al. 1996). In the absence of the ECD, the TMD domain assumes an energetically favorable, stable conformation different from that in the full-length wild type receptor thereby locking the serpentine region in an inactive state resistant to activating mutations and agonists. Thus, the LHR-ECD is required to maintain a distinct activation-competent conformation of the heptahelical region.

To gain further mechanistic insight, we asked whether the TSHR-ECD would render the LHR-TMD activation-competent for heptahelical activating mutations in the same way as the native LHR-ECD or whether it would act as a tethered inverse agonist on the LHR-TMD as observed for the wild type TSHR. Therefore, we generated TSHR-LHR chimeras consisting of the TSHR-ECD and the heptahelical LHR domain. As observed previously for analogous chimeras (Braun et al. 1991), our TSHR-LHR variants responded fully to TSH stimulation which is in accord with hormone-binding selectivity imparted by the respective ECD. Analysis of basal receptor activity revealed that TSHR-LHR chimeras harboring the above mentioned activating TMD-mutations exhibited a significantly reduced receptor activity compared with their wild type counterparts, suggesting a different influence of the TSHR-ECD on the LHR serpentine domain as the LHR-ECD. Two explanations may account for this observation: first, the TSHR-ECD acts on the heptahelical portion of the LHR as a tethered inverse agonist impairing the effect of activating TMD-mutations. Secondly, due to primary sequence differences between the LHR-ECD and the TSHR-ECD, the TSHR-ECD is not capable of supporting an LHR-TMD conformation susceptible to activating mutations.

In conclusion, our experiments support a new role for the LHR-ECD apart from hormone binding: the ECD facilitates an activation-competent conformation of the heptahelical region thereby challenging the prevailing concept that the hormone-binding ECD and the G protein-coupling serpentine region are structurally and functionally independent modules of glycoprotein hormone receptors. Our study provides evidence for a cooperative model with inseparable structural and functional interactions of both receptor modules. At present, it is not known whether the LHR-ECD is also required to maintain coupling of the TMD to phospholipase C (Gudermann et al. 1992). In the absence of the crystal structure of a hormone/holoreceptor complex, the identification of contact points between the ECD 
and the TMD will allow the correct orientation of these two receptor modules towards each other and will grant valuable insight into the mechanism of glycoprotein hormone receptor activation.

\section{Acknowledgements}

We thank Beate Junk for excellent technical assistance. We also thank Aaron J W Hsueh for providing the fulllength human LGR7 cDNA and Torsten Schöneberg for providing the V2LHR-pcDps cDNA. We also thank Irving Boime for the kind gift of rabbit anti-CG $\beta$ antiserum and the CG $\beta \alpha$ plasmid. This study was supported by a grant from the German-Israeli Foundation for Scientific Research and Development (GIF), the Deutsche Forschungsgemeinschaft (DFG) and the Nationales Genomforschungsnetz (NGFN-2; N2NV S30T09). The authors declare that there is no conflict of interest that would prejudice the impartiality of this scientific work.

\section{References}

Alvarez CA, Narayan P, Huang J \& Puett D 1999 Characterization of a region of the lutropin receptor extracellular domain near transmembrane helix 1 that is important in ligand-mediated signaling. Endocrinology 140 1775-1782.

Ascoli M, Fanelli F \& Segaloff DL 2002 The lutropin/choriogonadotropin receptor, a 2002 perspective. Endocrine Reviews 23 141-174.

Ben-Menahem D 2004 Single chain variants of the glycoprotein hormones and their receptors as tools to study receptor activation and for analogue design. Journal of Neuroendocrinology 16 171-177.

Bhowmick N, Huang J, Puett D, Isaacs NW \& Lapthorn AJ 1996 Determination of residues important in hormone binding to the extracellular domain of the luteinizing hormone/chorionic gonadotropin receptor by site-directed mutagenesis and modeling. Molecular Endocrinology 10 1147-1159.

Biebermann H, Schoneberg T, Krude H, Schultz G, Gudermann T \& Gruters A 1997 Mutations of the human thyrotropin receptor gene causing thyroid hypoplasia and persistent congenital hypothyroidism. Journal of Clinical Endocrinology and Metabolism 82 3471-3480.

Biebermann H, Schoneberg T, Schulz A, Krause G, Gruters A, Schultz G \& Gudermann T 1998 A conserved tyrosine residue (Y601) in transmembrane domain 5 of the human thyrotropin receptor serves as a molecular switch to determine G-protein coupling. FASEB Journal 12 1461-1471.

Braun T, Schofield PR \& Sprengel R 1991 Amino-terminal leucine-rich repeats in gonadotropin receptors determine hormone selectivity. EMBO Journal 10 1885-1890.

Cetani F, Tonacchera M \& Vassart G 1996 Differential effects of NaCl concentration on the constitutive activity of the thyrotropin and the luteinizing hormone/chorionic gonadotropin receptors. FEBS Letters 378 27-31.

Couture L, Remy JJ, Rabesona H, Troalen F, Pajot-Augy E, Bozon V, Haertle T, Bidart JM \& Salesse R 1996 A defined epitope on the human choriogonadotropin alpha-subunit interacts with the second extracellular loop of the transmembrane domain of the lutropin/choriogonadotropin receptor. European Journal of Biochemistry 241 627-632.

Fan QR \& Hendrickson WA 2005 Structure of human follicle-stimulating hormone in complex with its receptor. Nature 433 269-277.
Garcia-Campayo V, Kumar TR \& Boime I 2002 Thyrotropin, follitropin, and chorionic gonadotropin expressed as a single multifunctional unit reveal remarkable permissiveness in receptorligand interactions. Endocrinology 143 3773-3778.

Garcia-Campayo V, Jablonka-Shariff A \& Boime I 2004 A single-chain bifunctional gonadotropin analog is secreted from Chinese hamster ovary cells as two distinct bioactive species. Journal of Biological Chemistry 279 44286-44293.

Gruters A, Schoneberg T, Biebermann H, Krude H, Krohn HP, Dralle H \& Gudermann T 1998 Severe congenital hyperthyroidism caused by a germ-line neo mutation in the extracellular portion of the thyrotropin receptor. Journal of Clinical Endocrinology and Metabolism 83 1431-1436.

Gudermann T, Birnbaumer M \& Birnbaumer L 1992 Evidence for dual coupling of the murine luteinizing hormone receptor to adenylyl cyclase and phosphoinositide breakdown and $\mathrm{Ca}^{2+}$ mobilization. Studies with the cloned murine luteinizing hormone receptor expressed in L cells. Journal of Biological Chemistry $2674479-4488$.

Herpin A, Badariotti F, Rodet F \& Favrel P 2004 Molecular characterization of a new leucine-rich repeat-containing $\mathrm{G}$ proteincoupled receptor from a bivalve mollusc: evolutionary implications. Biochimica et Biophysica Acta 1680 137-144.

Hong S, Phang T, Ji I \& Ji TH 1998 The amino-terminal region of the luteinizing hormone/choriogonadotropin receptor contacts both subunits of human choriogonadotropin. I. Mutational analysis. Journal of Biological Chemistry 273 13835-13840.

Hong S, Ji I \& Ji TH $1999 a$ The alpha-subunit of human choriogonadotropin interacts with the exodomain of the luteinizing hormone/ choriogonadotropin receptor. Endocrinology $1402486-2493$.

Hong SH, Ji IH \& Ji TH $1999 b$ The beta-subunit of human choriogonadotropin interacts with the exodomain of the luteinizing hormone/choriogonadotropin receptor and changes its interaction with the alpha-subunit. Molecular Endocrinology 13 1285-1294.

Hsu SY, Kudo M, Chen T, Nakabayashi K, Bhalla A, van der Spek PJ, van Duin M \& Hsueh AJ 2000 The three subfamilies of leucine-rich repeat-containing $\mathrm{G}$ protein-coupled receptors (LGR): identification of LGR6 and LGR7 and the signaling mechanism for LGR7. Molecular Endocrinology 14 1257-1271.

Hsu SY, Nakabayashi K, Nishi S, Kumagai J, Kudo M, Sherwood OD \& Hsueh AJ 2002 Activation of orphan receptors by the hormone relaxin. Science 295 671-674.

Ji IH \& Ji TH 1991 Human choriogonadotropin binds to a lutropin receptor with essentially no N-terminal extension and stimulates cAMP synthesis. Journal of Biological Chemistry 266 13076-13079.

Karges B, Gidenne S, Aumas C, Haddad F, Kelly PA, Milgrom E \& de Roux N 2005 Zero-length cross-linking reveals that tight interactions between the extracellular and transmembrane domains of the $\mathrm{LH}$ receptor persist during receptor activation. Molecular Endocrinology 19 2086-2098.

Kosugi S, Mori T \& Shenker A 1996 The role of Asp578 in maintaining the inactive conformation of the human lutropin/choriogonadotropin receptor. Journal of Biological Chemistry 271 31813-31817.

Kremer H, Martens JW, van Reen M, Verhoef-Post M, Wit JM, Otten BJ, Drop SL, Delemarre-van de Waal HA, Pombo-Arias M, De Luca F et al. 1999 A limited repertoire of mutations of the luteinizing hormone $(\mathrm{LH})$ receptor gene in familial and sporadic patients with male LH-independent precocious puberty. Journal of Clinical Endocrinology and Metabolism 84 1136-1140.

Kundu GC, Ji I, McCormick DJ \& Ji TH 1996 Photoaffinity labeling of the lutropin receptor with synthetic peptide for carboxyl terminus of the human choriogonadotropin alpha subunit. Journal of Biological Chemistry 271 11063-11066.

Latronico AC, Abell AN, Arnhold IJ, Liu X, Lins TS, Brito VN, Billerbeck AE, Segaloff DL \& Mendonca BB 1998 A unique constitutively activating mutation in third transmembrane helix of luteinizing hormone receptor causes sporadic male gonadotropin-independent precocious puberty. Journal of Clinical Endocrinology and Metabolism 83 2435-2440. 
Laue L, Chan WY, Hsueh AJ, Kudo M, Hsu SY, Wu SM, Blomberg L \& Cutler GB Jr 1995 Genetic heterogeneity of constitutively activating mutations of the human luteinizing hormone receptor in familial male-limited precocious puberty. PNAS 92 1906-1910.

Liu G, Duranteau L, Carel JC, Monroe J, Doyle DA \& Shenker A 1999 Leydig-cell tumors caused by an activating mutation of the gene encoding the luteinizing hormone receptor. New England Journal of Medicine 341 1731-1736.

Moyle WR, Campbell RK, Myers RV, Bernard MP, Han Y \& Wang X 1994 Co-evolution of ligand-receptor pairs. Nature 368 251-255.

Muller J, Gondos B, Kosugi S, Mori T \& Shenker A 1998 Severe testotoxicosis phenotype associated with Asp578 $\rightarrow$ Tyr mutation of the lutrophin/choriogonadotrophin receptor gene. Journal of Medical Genetics 35 340-341.

Nakabayashi K, Kudo M, Kobilka B \& Hsueh AJ 2000 Activation of the luteinizing hormone receptor following substitution of Ser-277 with selective hydrophobic residues in the ectodomain hinge region. Journal of Biological Chemistry 275 30264-30271.

Narayan P, Gray J \& Puett D 2000 A biologically active single chain human chorionic gonadotropin analog with altered receptor binding properties. Endocrinology $14167-71$.

Narayan P, Gray J \& Puett D 2002 Yoked complexes of human choriogonadotropin and the lutropin receptor: evidence that monomeric individual subunits are inactive. Molecular Endocrinology 16 2733-2745.

Nishi S, Nakabayashi K, Kobilka B \& Hsueh AJ 2002 The ectodomain of the luteinizing hormone receptor interacts with exoloop 2 to constrain the transmembrane region: studies using chimeric human and fly receptors. Journal of Biological Chemistry 277 3958-3964.

Phang T, Kundu G, Hong S, Ji I \& Ji TH 1998 The amino-terminal region of the luteinizing hormone/choriogonadotropin receptor contacts both subunits of human choriogonadotropin. II. Photoaffinity labeling. Journal of Biological Chemistry 273 13841-13847.

Rapoport B, Chazenbalk GD, Jaume JC \& McLachlan SM 1998 The thyrotropin (TSH) receptor: interaction with TSH and autoantibodies. Endocrine Reviews 19 673-716.

Salomon Y, Londos C \& Rodbell M 1974 A highly sensitive adenylate cyclase assay. Analytical Biochemistry 58 541-548.

Sangkuhl K, Schulz A, Schultz G \& Schoneberg T 2002 Structural requirements for mutational lutropin/choriogonadotropin receptor activation. Journal of Biological Chemistry 277 47748-47755.

Schoneberg T, Sandig V, Wess J, Gudermann T \& Schultz G 1997 Reconstitution of mutant V2 vasopressin receptors by adenovirus-mediated gene transfer. Molecular basis and clinical implication. Journal of Clinical Investigation 100 1547-1556.

Schulz A, Schoneberg T, Paschke R, Schultz G \& Gudermann T 1999 Role of the third intracellular loop for the activation of gonadotropin receptors. Molecular Endocrinology 13 181-190.
Smits G, Campillo M, Govaerts C, Janssens V, Richter C, Vassart G, Pardo L \& Costagliola S 2003 Glycoprotein hormone receptors: determinants in leucine-rich repeats responsible for ligand specificity. EMBO Journal 22 2692-2703.

Sugahara T, Pixley MR, Minami S, Perlas E, Ben-Menahem D, Hsueh AJ \& Boime I 1995 Biosynthesis of a biologically active single peptide chain containing the human common alpha and chorionic gonadotropin beta subunits in tandem. PNAS 92 2041-2045.

Thomas D, Rozell TG, Liu X \& Segaloff DL 1996 Mutational analyses of the extracellular domain of the full-length lutropin/choriogonadotropin receptor suggest leucine-rich repeats 1-6 are involved in hormone binding. Molecular Endocrinology 10 760-768.

Van Sande J, Massart C, Costagliola S, Allgeier A, Cetani F, Vassart G \& Dumont JE 1996 Specific activation of the thyrotropin receptor by trypsin. Molecular and Cellular Endocrinology 119 161-168.

Vassart G, Pardo L \& Costagliola S 2004 A molecular dissection of the glycoprotein hormone receptors. Trends in Biochemical Sciences 29 119-126.

Vlaeminck-Guillem V, Ho SC, Rodien P, Vassart G \& Costagliola S 2002 Activation of the cAMP pathway by the TSH receptor involves switching of the ectodomain from a tethered inverse agonist to an agonist. Molecular Endocrinology 16 736-746.

Xie YB, Wang H \& Segaloff DL 1990 Extracellular domain of lutropin/choriogonadotropin receptor expressed in transfected cells binds choriogonadotropin with high affinity. Journal of Biological Chemistry 265 21411-21414.

Yano K, Kohn LD, Saji M, Kataoka N, Okuno A \& Cutler GB Jr 1996 A case of male-limited precocious puberty caused by a point mutation in the second transmembrane domain of the luteinizing hormone choriogonadotropin receptor gene. Biochemical and Biophysical Research Communications 220 1036-1042.

Zhang ML, Sugawa H, Kosugi S \& Mori T 1995 Constitutive activation of the thyrotropin receptor by deletion of a portion of the extracellular domain. Biochemical and Biophysical Research Communications 211 205-210.

Zhang M, Tong KP, Fremont V, Chen J, Narayan P, Puett D, Weintraub BD \& Szkudlinski MW 2000 The extracellular domain suppresses constitutive activity of the transmembrane domain of the human TSH receptor: implications for hormone-receptor interaction and antagonist design. Endocrinology 141 3514-3517.

Zhang M, Mizrachi D, Fanelli F \& Segaloff DL 2005 The formation of a salt bridge between helices 3 and 6 is responsible for the constitutive activity and lack of hormone responsiveness of the naturally occurring L457R mutation of the human lutropin receptor. Journal of Biological Chemistry 280 26169-26176.

Received in final form 20 November 2006 Accepted 30 November 2006 